\title{
Fine Needle Aspiration Cytology of Primary and Secondary Testicular Lymphoma and its Clinical Mimickers- A Definite Indication
}

\author{
Debasis Gochhait, Shailesh Kekade, Jinkala Sree Rekha* and Bhawana Ashok Badhe
}

Department of Pathology, Jawaharlal Institute of Postgraduate Medical Education and Research, Puducherry

\section{ABSTRACT}

Albeit being rare, the testicular lymphoma is the most common testicular malignancy in elders. In early stages, its symptoms are non-specific and can mimic other underlying diseases. The available knowledge of cytology on this entity is not adequate. In case when a clinician comes across a testicular enlargement case, a decision has to be made when to send the patient for FNAC. Similarly, the pathologist who is assessing the patient should also make a decision whether to perform Fine Needle Aspiration Cytology (FNAC) on the patient or not, and what morphology is expected on cytological smears to be able to confidently call it testicular lymphoma. We have undertaken this study to serve the purpose of enhancing the sparse knowledge available on this disease, dealt with its multiorgan involvement, and explained how FNAC is a valuable utility in testicular enlargement cases in which serological markers of testicular malignancy are negative.

Keywords: Testicular Lymphoma, Primary, Secondary, Fine Needle Aspiration Cytology (FNAC)

\section{Introduction}

The most common malignancy of testis in elderly age group is lymphoma, however, it is rare and there is a scarcity of documented cases on Fine Needle Aspiration Cytology (FNAC) of testicular lymphoma in the literature. ${ }^{[1-5]}$ Though testicular FNA is contraindicated in germ cell tumors due to needle tract seedling, we would like to emphasize that primary or secondary hematolymphoid malignancy is one definite indication for FNA cytology because it is an easy and inexpensive procedure as compared to biopsy. In addition to that we can also collect adequate material for categorization of the lymphoma by flow cytometry or cell block technique. Many a times a pathologist may come across a testicular lymphoma when testis/ epididymis is subjected for FNA with a clinical diagnosis of infection/ tuberculosis. We would like to share our experience with three cases of testicular lymphoma - one primary and other two secondary involvements.

\section{Case Report}

Case 1: An 80-year-old patient reported to the FNAC clinic with a rapidly growing, mildly tender right testicular mass of size $7 \times 6 \times 5 \mathrm{~cm}$ for one month. The epididymis was not palpable and the other testis was normal in size (Figure 1A). All germ cell markers were negative on serology. With a clinical diagnosis of epididymo-orchitis FNA was performed from the testis. May Grünwald Giemsa (MGG) and Papanicolaou (Pap) stained moderately cellular smears revealed medium to large atypical lymphoid cells characterised by round to irregular nuclear membrane, coarse chromatin, prominent nucleoli in occasional cells, and scant basophilic cytoplasm. The background showed lympho-glandular bodies and many clusters of Sertoli cells (Figure 2A \&B). Hence, it was reported as highgrade Non-Hodgkin Lymphoma (NHL) of the right testis. The orchidectomy showed diffuse enlargement of testis with fleshy appearance (Figure IB). Haematoxylin and Eosin-stained sections revealed diffuse sheets of medium sized atypical lymphoid cells with coarse chromatin, inconspicuous nucleoli and scant cytoplasm (Figure IID). After immunohistochemistry, the final diagnosis was given as primary testicular Diffuse Large B Cell Lymphoma (DLBCL) - Non-Germinal centre (NGC). The patient is under follow up for 3 months without any therapy.

Case 2: A 69-year-old patient presented to FNAC clinic with right inguinal node swelling $(4 \times 3 \mathrm{~cm})$ and a hard mildly tender right testicular mass $(12 \times 10 \times 9 \mathrm{~cm})$ for 6 weeks. The serology for germ cell tumors was negative. FNAC was performed from inguinal node and right testis and smears showed similar features as in case 1. Hence, the cytological diagnosis of high-grade NHL of node with involvement of right testis was rendered. On a later date the nodal biopsy was confirmed as DLBCL -NGC type on histopathology (refer tablel for marker profile). This is a patient with secondary testicular DLBCL. The patient is being treated with $\mathrm{RCHOP}$ regimen.

Case 3: A 66-year male patient presented with a slow growing right orbital swelling for 3 months (Figure 3A). On clinical evaluation the patient had right inguinal lymphadenopathy along with ipsilateral testicular 
enlargement (Figure 3B). The clinical diagnosis was NHL with generalized dissemination. FNAC from the right orbit, inguinal $\mathrm{LN}$ and testis similar morphology of a high-grade NHL (Figure 4 A \& B). Later a biopsy was performed from the orbital mass which was confirmed as
DLBCL - NGC type. This is also a patient with secondary testicular DLBCL. Refer to table 1 for clinicopathological details and marker profile of the three cases.

Consent for FNAC and biopsy from the patients was taken according to the institutional guidelines.

Table 1: Clinicopathological profile of patients with testicular lymphoma.

\begin{tabular}{|c|c|c|c|}
\hline Parameter & Case 1 & Case 2 & Case 3 \\
\hline Age & $80 y$ & $69 y$ & $66 y$ \\
\hline Site & Unilateral (Right testis) & Unilateral (Left testis) & Unilateral (Right testis) \\
\hline Sites involved & $\begin{array}{l}\text { Ipsilateral epididymal region } \\
\text { enlargement in continuity with } \\
\text { testicular parenchyma (Figure } \\
\text { 1A) }\end{array}$ & $\begin{array}{l}\text { Ipsilateral inguinal } \\
\text { lymphadenopathy }\end{array}$ & $\begin{array}{l}\text { Ipsilateral inguinal } \\
\text { lymphadenopathy and ipsilateral } \\
\text { orbital mass. (Figure } 3 \mathrm{~A} \& \mathrm{~B} \text { ) }\end{array}$ \\
\hline Indication of FNAC & $\begin{array}{l}\text { Mild tender enlargement of the } \\
\text { right testicular region with all } \\
\text { germ cell markers negative. }\end{array}$ & $\begin{array}{l}\text { Inguinal node FNAC } \\
\text { was NHL, so testicular } \\
\text { FNA was performed } \\
\text { for confirmation of } \\
\text { infiltration. }\end{array}$ & $\begin{array}{l}\text { Painless development of right } \\
\text { sided orbital mass- proved to be } \\
\text { NHL. Testicular mass and inguinal } \\
\text { lymphadenopathy were elicited on } \\
\text { clinical examination. }\end{array}$ \\
\hline $\begin{array}{l}\text { Presentation of all the } \\
\text { sites. }\end{array}$ & Only testicular enlargement & $\begin{array}{l}\text { Mild tender enlargement } \\
\text { of the left scrotal sac } \\
\text { following inguinal } \\
\text { lymphadenopathy) }\end{array}$ & $\begin{array}{l}\text { Right orbital proptosis followed } \\
\text { by inguinal and testicular } \\
\text { enlargement. }\end{array}$ \\
\hline FNAC morphology & $\begin{array}{l}\text { High grade NHL (markers not } \\
\text { attempted as orchidectomy was } \\
\text { planned after FNA report) }\end{array}$ & $\begin{array}{l}\text { High grade NHL } \\
\text { (markers not attempted } \\
\text { as biopsy was already } \\
\text { done from the inguinal } \\
\text { mass) }\end{array}$ & $\begin{array}{l}\text { High grade NHL (markers not } \\
\text { attempted as biopsy was already } \\
\text { done from the orbital mass) }\end{array}$ \\
\hline $\begin{array}{l}\text { Biopsy site and } \\
\text { Diagnosis }\end{array}$ & $\begin{array}{l}\text { Primary Testicular } \\
\text { DLBCL-NGC type } \\
\text { (specimen-right orchidectomy) }\end{array}$ & $\begin{array}{l}\text { Secondary testicular } \\
\text { DLBCL-NGC type in a } \\
\text { c/o nodal DLBCL } \\
\text { (specimen- inguinal } \\
\text { lymph node core biopsy) }\end{array}$ & $\begin{array}{l}\text { Secondary testicular DLBCL-NGC } \\
\text { type } \\
\text { (specimen-orbital mass biopsy) }\end{array}$ \\
\hline $\begin{array}{l}\text { Immunohistochemistry } \\
\text { profile }\end{array}$ & $\begin{array}{l}\text { CD20+, CD3-, CD10-, BCL6- } \\
\text {, MUM1+(>30\%), Ki67-90\%, } \\
\text { BCL2+, Tdt- }\end{array}$ & $\begin{array}{l}\text { CD20+, CD3-, CD10- } \\
\text {, BCL6+(>30\%), } \\
\text { MUM1+(>30\%), Ki67- } \\
60 \%, \text { CD30-, C-MYC-, } \\
\text { Alk1- }\end{array}$ & $\begin{array}{l}\text { CD20+, CD3-, CD10-, } \\
\text { BCL6+(>30\%), MUM1+(>30\%) } \\
\text { Ki67- } 70 \%\end{array}$ \\
\hline Bone marrow status & Uninvolved & Uninvolved & Uninvolved \\
\hline CSF involvement & Test not done & Uninvolved & Uninvolved \\
\hline Treatment & $\begin{array}{l}\text { Right orchidectomy + } \\
\text { chemotherapy }\end{array}$ & Chemotherapy & Chemotherapy \\
\hline
\end{tabular}

FNAC - Fine needle aspiration cytology; NHL - Non Hodgkin Lymphoma; DLBCL-Diffuse large B cell lymphoma; NGC - Non-germinal centre type 


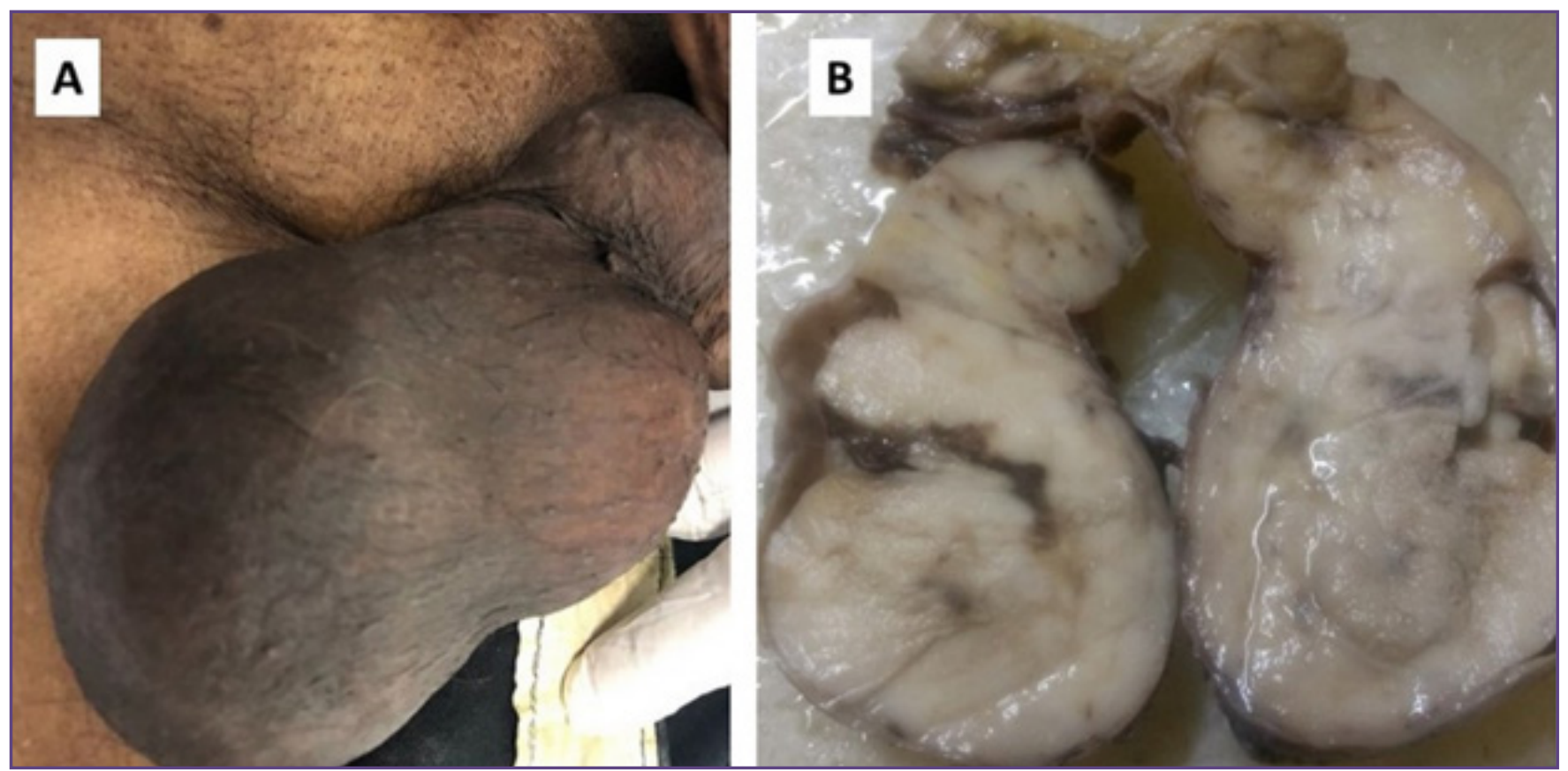

Fig. 1: Unilateral right testicular enlargement in primary testicular lymphoma. 1B: The gross image of the testicular resection showing a homogenous fleshy mass involving the whole of the parenchyma..
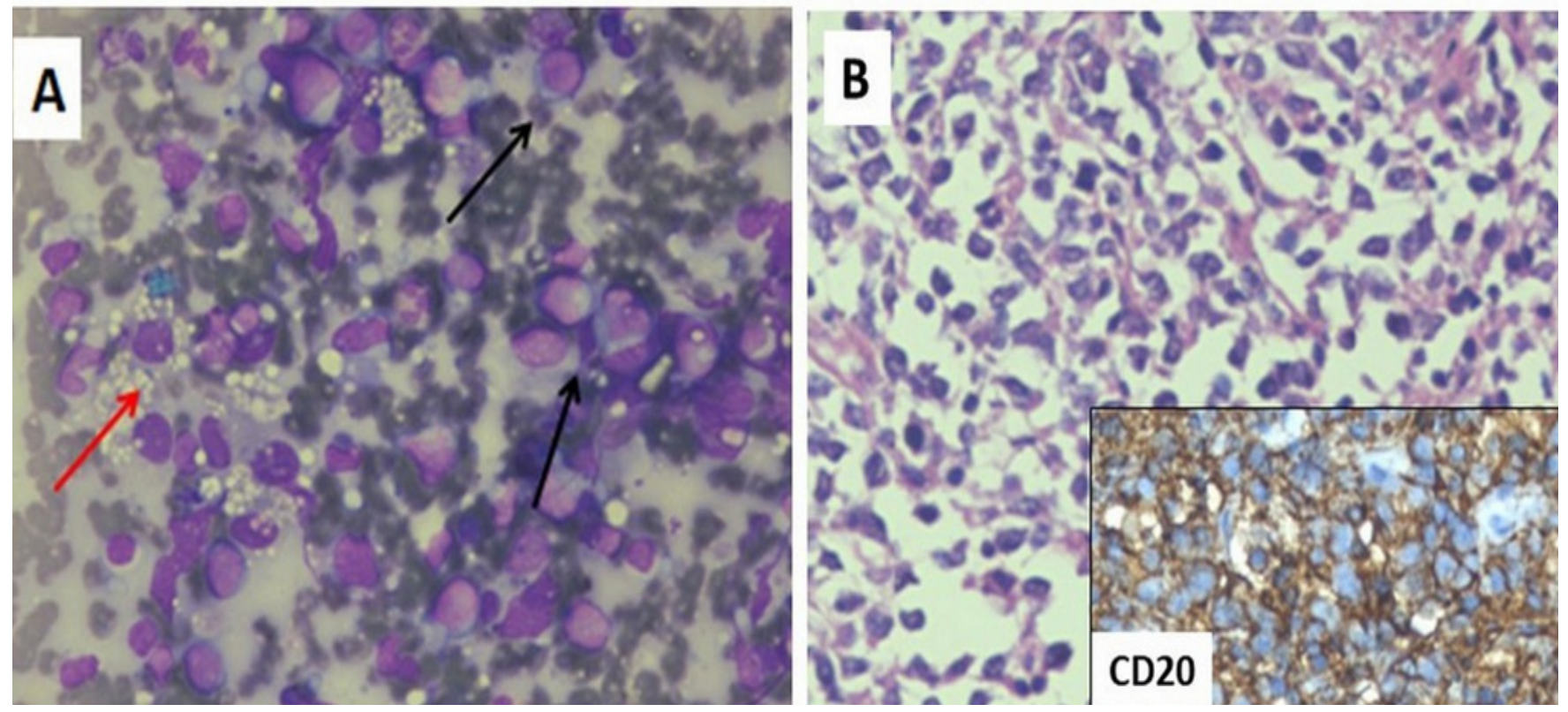

Fig. 2: A: FNAC smears showing large atypical lymphoid cells with moderate pleomorphism, irregular nuclear membrane, scanty basophilic cytoplasm (black arrows) admixed with the Sertoli cells having abundant vacuolated cytoplasm (red arrows) (400 X MGG). B: Sections of the testicular resection shows atypical lymphoid cells in sheets (200XH\&E); Inset shows strong and diffuse positive for CD20 (200X DAB). 


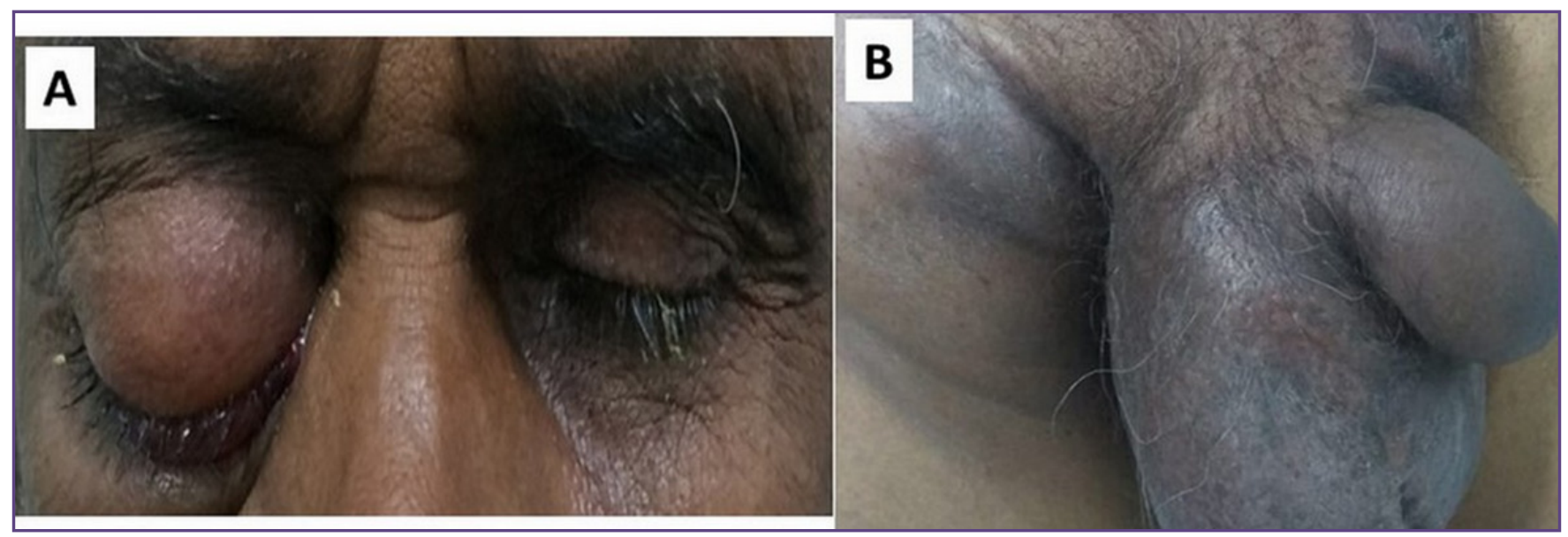

Fig. 3: A: Right orbit with proptosis due to a retrobulbar mass (primary clinical presentation) while testicular enlargement secondary to the inguinal lymphadenopathy is seen in Fig B.

\section{Discussion}

Primary testicular lymphoma is a rare malignancy which accounts for around $1-9 \%$ of all testicular neoplasms, whereas only $1-2 \%$ of all NHL cases are primary testicular lymphoma. ${ }^{[2-5]}$ It is the most common malignancy in patients more than 50 years of age however; it is not an exclusive disease of elderly. ${ }^{[1-3]}$ Although $85 \%$ of all testicular lymphomas are reported in patients more than 60 years of age as observed in our patients, Ratkal et al reported a rare presentation of primary testicular lymphoma in a young patient of 27 years. ${ }^{[5]}$ Lymphoma is also the most common bilateral tumour of the testes seen in $20 \%$ of cases. ${ }^{[1,3,5]}$ We detected unilateral involvement in all the three cases. It is common to come across the involvement of epididymis and the cord, as well as vascular invasion in lymphoma. ${ }^{[5]}$

The patients most commonly present with a painless slow growing testicular swelling, with occasional presentation like scrotal pain, hydrocoele, abdominal pain and ascites. ${ }^{[2,3,5]} \mathrm{B}$ symptoms (fever, night sweat and weight loss) were seen in advanced stages only and none of our patients had such symptoms. Primary testicular lymphoma shares the same immunophenotypic features with the corresponding histopathological variants arising either in lymphnodes or extranodal sites..$^{[3]}$ The three common subtypes of testicular lymphoma include DLBCL, Burkitt lymphoma (BL) and follicular lymphoma (FL). FNAC smears overall are usually cellular and show cytological picture similar to that seen in cases of nodal lymphoma, except for the presence of Sertoli cells with cytoplasmic vacuolisation, which are expressed in response to the increased intratubular pressure. ${ }^{[7]}$

Testicular lymphoma in most cases is easily distinguishable from germ cell cancer (GCT) on morphologic grounds, nevertheless the common mimickers are Seminoma,
Spermatocytic seminoma, granulomatous and viral Orchitis. ${ }^{[2,3,5,6]}$ Seminoma can show dyscohesive cells admixed with lymphoplasmacytic infiltrate but the younger age, lack of lymphoglandular bodies, tigroid background; clear glycogen rich cytoplasm and its PAS-positivity are important clues to diagnose Seminoma. ${ }^{[7]}$ Leukocyte Common Antigen (LCA) is useful in difficult cases. ${ }^{[2,8]} \mathrm{In}$ spermatocytic seminoma, the cells are again dyscohesive without any architecture, polymorphous (small, medium and large) in appearance, with a cleaner background, low mitotic rate and absence of lymphocytes ${ }^{[2,9]}$ Another feature that differentiates secondary lymphoma from primary GCT is the inguinal lymph node involvement which is almost non-existent in GCT of testis. Viral and granulomatous orchitis are composed of a heterogeneous population of benign appearing lymphoid cells, which is in contrast to lymphoma, composed of a more homogeneous population of malignant appearing lymphoid cells. ${ }^{[2]}$

The histomorphology of both primary and secondary testicular lymphoma is mostly that of DLBCL in adults where as in paediatric cases it may be like Burkitt lymphoma with cytoplasmic vacuoles or blast like in lymphoblastic lymphoma. ${ }^{[1]}$ The presence of pseudo glandular pattern in highly cellular lesions of lymphoma aspirates, is another feature which may cause diagnostic dilemma with other small round cell tumors as epithelial malignancies are rare in testis. The background should be looked for lymphoglandular bodies and age is an important clue in such cases. The most common subtype of primary DLBCL is the NGC type and this is attributed as one reason for their aggressive behaviour. ${ }^{[10]}$ The patients of testicular lymphoma should be thoroughly evaluated for the systemic dissemination especially in pelvic and mediastinal lymph nodes, Waldeyer's ring and skin along 
with special attention to central nervous system (CNS) because CNS involvement is seen in $30 \%$ of cases $[3,5]$. Management includes aggressive chemotherapy (mostly R-CHOP regimen), irradiation of the contralateral testis, as well as prophylactic CNS irradiation. ${ }^{[2,3,5]}$ The prognosis is however poor in high grade types of lymphoma, or their advanced staging, with the survival being at 9-12 months. ${ }^{[3,5]}$ Orchiectomy has a role in testis limited primary unilateral involvement because it removes the bloodtestis barrier, which gives easier access to the systemic chemotherapy ${ }^{[2]}$ Another advantage is that the patient may be totally cured if its localized and low-grade disease. In the study conducted by the International Extranodal Lymphoma Study Group (IELSG) on 373 cases of Primary Testicular Lymphoma, the factors determining a longer overall survival are, low/low-intermediate risk, absence of B symptoms, anthracycline based chemotherapy, and prophylactic radiotherapy of the scrotum. ${ }^{[3]}$

\section{Conclusion}

Proper clinical, radiological and pathological assessments are an integral part of the assessment of a testicular mass in elderly patients with negative germ cell markers. We do not recommend FNA in all testicular tumors/masses, however when the clinical suspicion is lymphoma/ inflammation in an elderly male it can be performed for confirmation of the same.

\section{Acknowledgements}

We would like to acknowledge our colleagues from General surgery and Medical Oncology

\section{Funding}

Nil

\section{Competing Interests \\ Nil}

\section{References}

1. Smith Z, Werntz R, Eggener S. Testicular Cancer. Medical Clinics of North America. 2018;102:251-264.

2. Kim H. Primary testicular diffuse large B-cell lymphoma: A case report focusing on touch imprint cytology and a nongerminal center B-cell-like phenotype. Exp Ther Med. 2013; 6:33-36.

3. Vitolo U, Ferreri A, Zucca E. Primary testicular lymphoma. Crit Rev Oncol Hematol. 2008;65:183-189.

4. Horne M, Adeniran A. Primary Diffuse Large B-Cell Lymphoma of the Testis. Arch Pathol Lab Med. 2011;135:1363-1367.

5. Ratkal V, Chawla A, Mishra D, Monappa V. Testicular nonHodgkin's lymphoma presenting in a young adult. Case Reports. 2015; doi:10.1136/ bcr-2014-208633

6. Huyghe E, Matsuda T, Thonneau P. Increasing Incidence of Testicular Cancer Worldwide: A Review. J Urol. 2003;170:511.

7. Perez-Guillermo M, SolaPérez J. Aspiration cytology of palpable lesions of the scrotal content. Diagn Cytopathol. 1990;6:169-177.

8. Pandey A, Nandini N, Jha A, Manjunath G. Fine needle aspiration cytology and cell block in the diagnosis of seminoma testis. J Cytol. 2011;28:39.

9. Saran R, Banerjee A, Gupta S, Rajwanshi A. Spermatocytic seminoma: A cytology and histology case report with review of the literature. Diagn Cytopathol. 1999;20:233-236.

10. Al-Abbadi M A, Hattab E M,Tarawneh M S, Amr S S, Orazi A and Ulbright T M. Primary testicular diffuse large B-cell lymphoma belongs to the nongerminal center B-cell-like subgroup: a study of 18 cases. Modern Pathology.2006;19:1521-1527.

*Corresponding author:

Dr. J. Sree Rekha, Associate Professor.,Dept of Pathology, Institute block, JIPMER., Puducherry- 605006

Phone: +91 8903306817

Email: sree.path177@gmail.com

Date of Submission : 28/08/2020

Date of Revision : $: 24 / 12 / 2020$

Date of Acceptance : 01/01/2021

Financial or other Competing Interests: None. 